\title{
Split Ring Resonator-based Bandpass Filter with Multi- Transmission Zeros and Flexibly Controllable Bandwidth Using Multipath Source-Load Couplings
}

\author{
Eun-Seong KIM, Kishor Kumar ADHIKARI, Nam-Young KIM \\ Dept. of Electronic Engineering, Kwangwoon University, Kwangwoon-ro 20, Nowon-gu, Seoul, S. Korea \\ esk@kw.ac.kr, kishordhkr@live.com, nykim@kw.ac.kr \\ Submitted March 16, 2018 / Accepted September 17, 2018
}

\begin{abstract}
This paper presents a high-selectivity compact microstrip bandpass filter (BPF) with a flexibly controllable bandwidth, based on multi-path source-load couplings and a square-type split-ring resonator (STSRR). An STSRR, which is enclosed between the capacitively coupled source and load transmission feed lines, forms the structure of the proposed BPF. The main advantages of the proposed BPF lie in its simple structure and high selectivity due to multiple transmission zeros generated by multipath source-load couplings based on STSRR-enabled magnetic coupling between the feed lines with dual capacitive couplings. In addition, the bandwidth of the proposed BPF can be flexibly controlled by varying the magnetic coupling gap between the STSRR and the feed lines. The measured pass-band insertion and return loss of 0.83 and $27.23 \mathrm{~dB}$, respectively, for a prototype BPF with a central frequency of $3.83 \mathrm{GHz}$ and corresponding bandwidth of $12.98 \%$, demonstrate the validity of the proposed method.
\end{abstract}

\section{Keywords}

Bandpass filter, compact size, multipath coupling, selectivity, split ring resonator, transmission zero

\section{Introduction}

Easy design, simple layout structure, and the flexibility to control the central frequency and corresponding bandwidth, as well as size miniaturization, are the ongoing research trends for microwave bandpass filters (BPFs) to meet the increasing demands of emerging wireless applications. The split-ring resonator (SRR), which was originally proposed by Pendry [1], has demonstrated advantageous features of small electrical size, and easy design and synthesis, and therefore, has emerged as a front-runner for developing high-performance BPFs [2], [3]. Furthermore, its shape can be easily modified and a complementary SRR can be internally embedded to develop BPFs with good performance. Several previously reported works on SRR also reflect its continuous evolvement [4-6].
Selectivity, which is one of the most critical issues for practical applications of BPFs, necessitates a proper coupling mechanism to achieve a low insertion loss and high return loss in the pass band and generate a number of transmission zeros in the stop band while maintaining a compact filter size. Among the most commonly reported coupling techniques, such as cross-coupling, source-load coupling, and mixed electric/magnetic coupling, source-load coupling was found to be suited to multiple practical applications [7], [8], as they can use multipath couplings to generate multiple transmission zeros, and thus, achieve high skirt selectivity in the stop band.

In this work, we present a microstrip BPF for applications in modern wireless and satellite communication systems using a square-type split ring resonator (STSRR). The significant novelty of the developed BPF lies in its newly proposed coupling mechanism, which consists of an inductive coupling between the STSRR and the source-load transmission lines, as well as dual capacitive coupling splits in the transmission lines; thereby exploiting the multipath coupling effects to introduce four transmission zeros near the pass-band to generate a wide stop-band performance. Additionally, the location of the transmission zeros can be controlled, and the pass-band bandwidth can be effectively controlled by adjusting the strength of the source-load coupling [9]. To verify the validity of the proposed method, a prototype BPF was designed, fabricated, and the simulated and measured S-parameters were compared.

\section{BPF Layout Design, Simulation, and Analysis}

The resonant frequency $f_{\mathrm{r}}$ of an STSRR, whose typical layout with dimensional parameters $l_{\mathrm{x}}, l_{\mathrm{y}}, d$, and $w$ is depicted in Fig. 1(a), can be predicted using the following equation [10], [11]:

$$
f_{\mathrm{r}}=\frac{1}{2 \pi \sqrt{L_{\mathrm{r}} C_{\mathrm{r}}}}=\frac{c}{2 \pi \sqrt{\varepsilon_{\text {eff }}} \sqrt{l_{\mathrm{x}} l_{\mathrm{y}}}} \sqrt{\frac{d}{w}}
$$




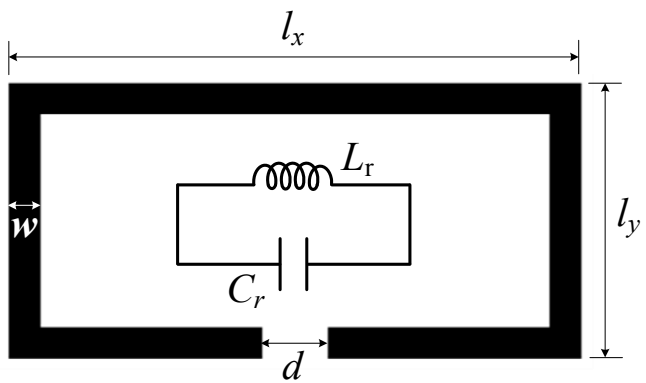

(a)

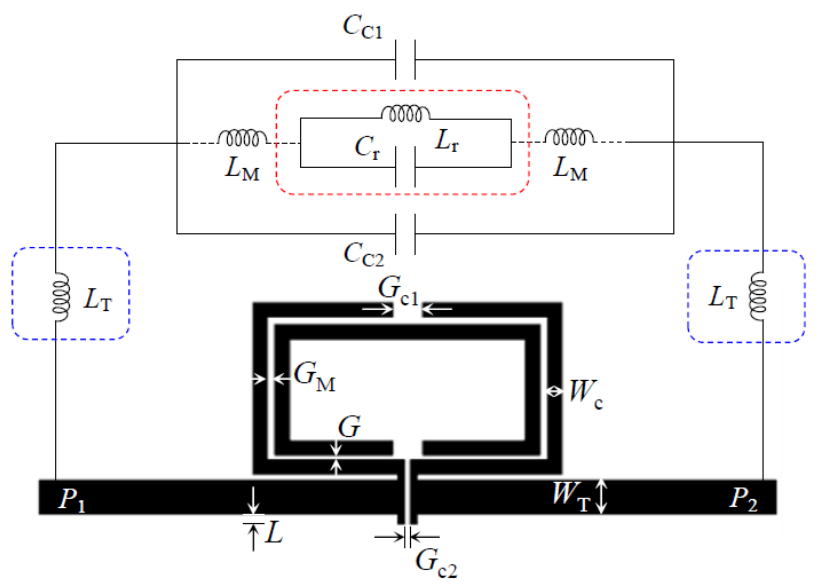

(b)

Fig. 1. Proposed high-selectivity BPF using multipath coupling of the STSRR: (a) Layout configuration of a typical STSRR, (b) layout of the proposed BPF and its equivalent circuit.

where $L_{\mathrm{r}}$ and $C_{\mathrm{r}}$ denote the resonator's equivalent inductance and capacitance, respectively; $c$ is the speed of light; and $\varepsilon_{\text {eff }}$ is the effective dielectric constant of the microstrip line at the resonant frequency.

To synthesize the proposed BPF, an STSRR was embedded inside two folded signal feed lines shunt-connected with capacitively coupled $50-\Omega$ transmission lines as shown in Fig. 1(b). Therefore, the STSRR provides an inductive coupling path between the source-load transmission lines. Additionally, a split was created between the $50-\Omega$ transmission lines to utilize their capacitive coupling. Thus, the proposed BPF layout arrangement utilizes multipath source-load coupling effects using an inductive coupling gap $G_{\mathrm{M}}$ and two capacitive coupling gaps, $G_{\mathrm{C} 1}$ and $G_{\mathrm{C} 2}$. Figure 1(b) also depicts the equivalent circuit of the proposed BPF in terms of a tuned circuit $L_{\mathrm{r}} C_{\mathrm{r}}$ resonating at the central frequency of the proposed BPF and determined by the embedded STSRR. $L_{\mathrm{T}}$ and $L_{\mathrm{M}}$ represent the net inductance of the signal feed lines shunted with transmission lines and its mutual inductance with the STSRR, respectively. $C_{\mathrm{C} 1}$ and $C_{\mathrm{C} 2}$ represent the net capacitance due to the capacitive coupling effect between the folded signal feed lines and the source-load transmission lines, respectively. To generate a central frequency of $3.85 \mathrm{GHz}$, the layout dimensions of the proposed BPF were optimized using the Sonnet full-wave electromagnetic software; the simulated S-parameters are shown in Fig. 2. The results indicate a pass-band insertion and return loss of $0.77 \mathrm{~dB}$

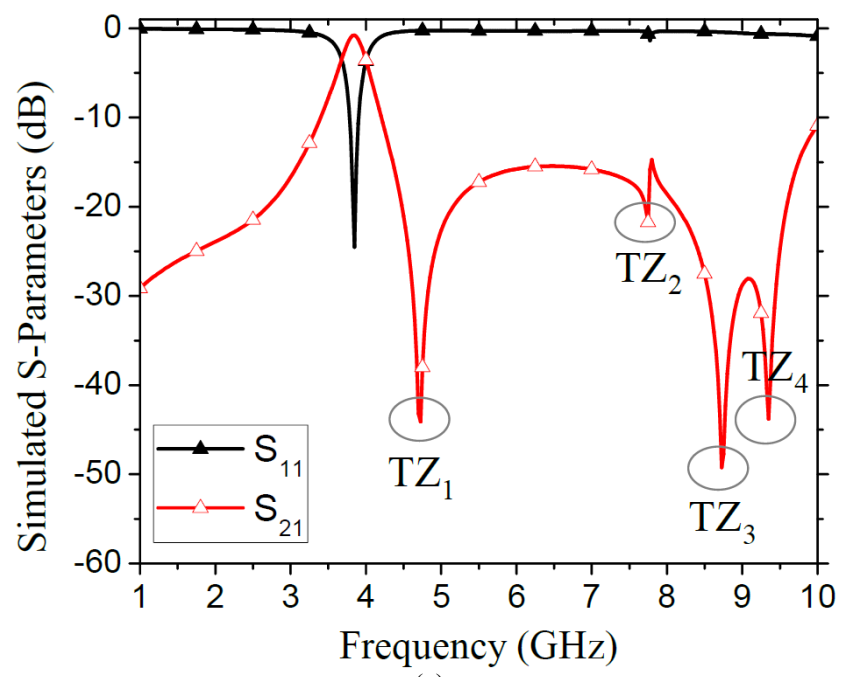

(a)

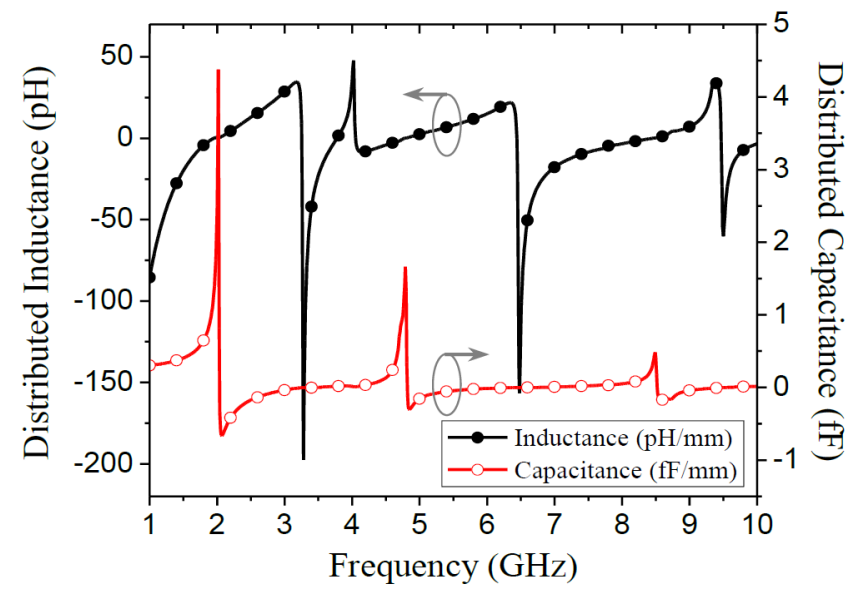

(b)

Fig. 2. (a) Simulated S-parameters of the proposed BPF and (b) distributed inductance $(\mathrm{pH} / \mathrm{mm})$ and capacitance $(\mathrm{fF} / \mathrm{mm})$ calculated using simulated S-parameters.

and $28.5 \mathrm{~dB}$, respectively. Four transmission zeros $\left(T Z_{1}\right.$, $T Z_{2}, T Z_{3}$, and $T Z_{4}$ ) appeared at 4.7, 7.75, 8.6, and $9.35 \mathrm{GHz}$, with a suppression level of $45.7,21.9,48.1$, and $41.9 \mathrm{~dB}$, respectively. Thus, the proposed BPF exhibited an excellent selectivity performance for both pass band and stop band. The distributed inductance and capacitance of the optimized BPF, which were calculated using the simulated S-parameters [12] and are shown in Fig. 2, indicated a net inductance and capacitance of $66.26 \mathrm{pH}$ and $25 \mathrm{fF}$, respectively at the central frequency of $3.85 \mathrm{GHz}$ for a propagation length of $12.5 \mathrm{~mm}$.

S-parameters were simulated, and the results were analyzed for variations in the coupling gaps to study the impact of coupling gaps on the frequency response of the proposed BPF. The $G_{\mathrm{C} 1}$-based changes in the locations of transmission zeros, which are indicated by the simulated $\mathrm{S}_{21}$ and illustrated in Fig. 3 (a), show that $T Z_{1}, T Z_{3}$, and $T Z_{4}$ shifted upward when $G_{\mathrm{C} 1}$ increased. The upward shift of the transmission zeros positively correlated with the increase in $G_{\mathrm{C} 1}$ for a range of 0.8 to $2 \mathrm{~mm}$. However, the location of $T Z_{2}$ remained almost unchanged with $G_{\mathrm{C} 1}$ changes. The results, which are shown in Fig. 3(b) for the 


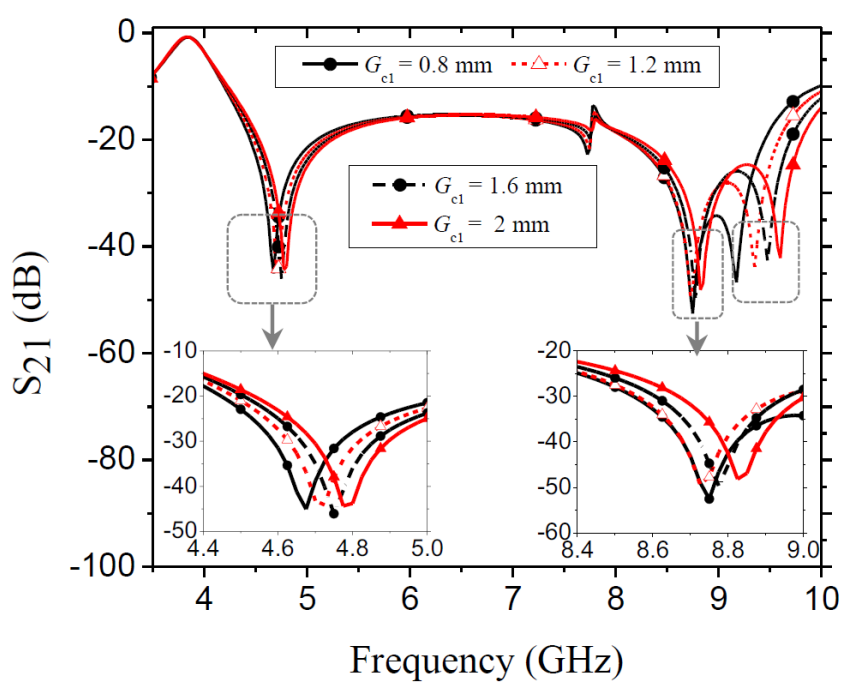

(a)

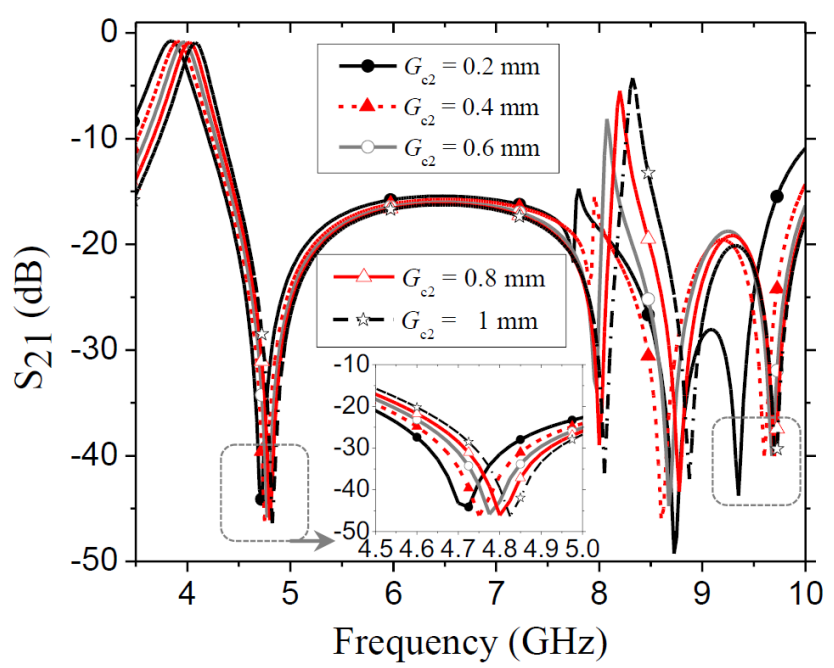

(b)

Fig. 3. Simulated $S_{21}$ to study the impact of variations of capacitive coupling strengths on the frequency selectivity of the proposed BPF: (a) Shifts in the locations of the transmission zeros with variations in $G_{\mathrm{Cl}}$, and (b) shifts in the locations of the transmission zeros with variations in $G_{\mathrm{C} 2}$.

changes in the locations of the transmission zeros with the variations in $G_{\mathrm{C} 2}$ from 0.2 to $1 \mathrm{~mm}$, indicate that $T Z_{1}$ exhibited a marked and positively correlated upward shift with an increase in $G_{\mathrm{C} 2}$. When $G_{\mathrm{C} 2}$ increased from 0.2 to $1 \mathrm{~mm}$, $T Z_{2}$ shifted from 4.8 to $5.4 \mathrm{GHz}$. There was almost no effect of the changes in $G_{\mathrm{C} 2}$ on the locations of $T Z_{2}$. Moreover, $T Z_{3}$ and $T Z_{4}$ disappeared when $G_{\mathrm{C} 2}$ was beyond $0.4 \mathrm{~mm}$.

The results for the effect of wide variations $(0.2$ to $2 \mathrm{~mm}$ ) of $G_{\mathrm{M}}$ on the proposed BPF performance, which are indicated by the simulated $\mathrm{S}_{21}$, are shown in Fig. 4(a). The results indicate strong dependences on $G_{\mathrm{M}}$ of the $T Z_{1}, T Z_{2}$, $T Z_{3}$, and $T Z_{4}$ locations as well as the $3-\mathrm{dB}$ pass-band bandwidth of the proposed BPF [13]. The transmission zeros exhibited marked upward shifts with the increase in $G_{\mathrm{M}}$. In addition, the upward shifts were maximized when $G_{\mathrm{M}}$ was maximized. Moreover, the $3-\mathrm{dB}$ bandwidth of the pass

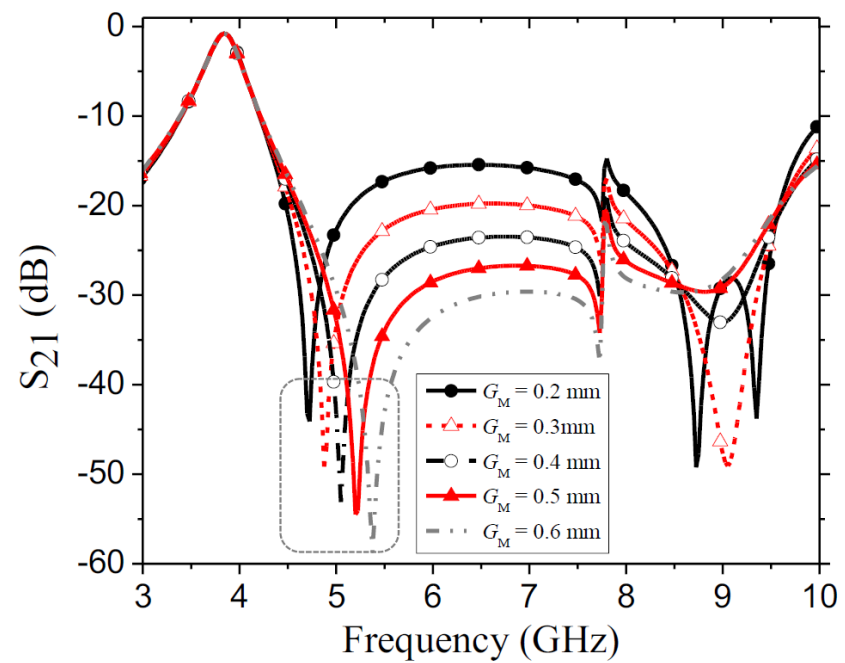

(a)

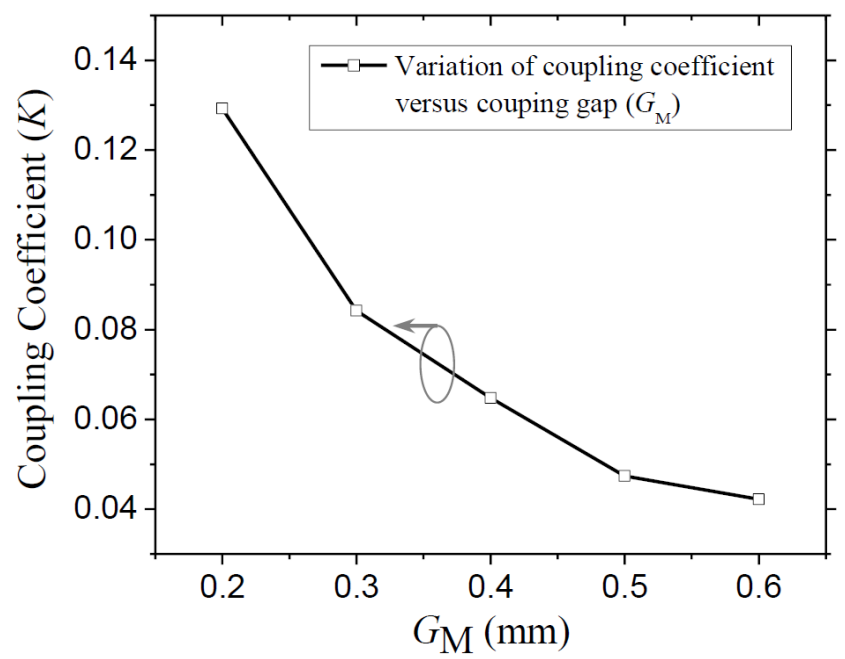

(b)

Fig. 4. Simulated $S_{21}$ to study the impact of variations of magnetic coupling strength on the frequency selectivity and the $3-\mathrm{dB}$ bandwidth of the proposed BPF: (a) Shifts in the locations of the transmission zeros and changes in pass-band bandwidths with variations in $G_{\mathrm{M}}$, and (b) changes in the coupling coefficient $K$ with variations in $G_{\mathrm{M}}$.

band significantly flattened with the decrease in $G_{\mathrm{M}}$, and therefore, with the increase in magnetic coupling level. Figure 4(b) depicts the coupling coefficient $K$ as a function of $G_{\mathrm{M}}$, where $K$ was calculated using the following equation [14]:

$$
K=\frac{f_{2}^{2}-f_{1}^{2}}{f_{2}^{2}+f_{1}^{2}}
$$

where $f_{1}$ and $f_{2}$ are the first and second resonant frequencies, respectively. The value of $K$ was 0.1293 and 0.0422 when $G_{\mathrm{M}}$ was 0.2 and $0.6 \mathrm{~mm}$, respectively.

Therefore, coupling coefficient of the proposed BPF exhibited a negative correlation with $G_{\mathrm{M}}$ and indicated that the 3-dB bandwidth of the proposed BPF can be flexibly controlled by varying the magnetic coupling level [15]. 


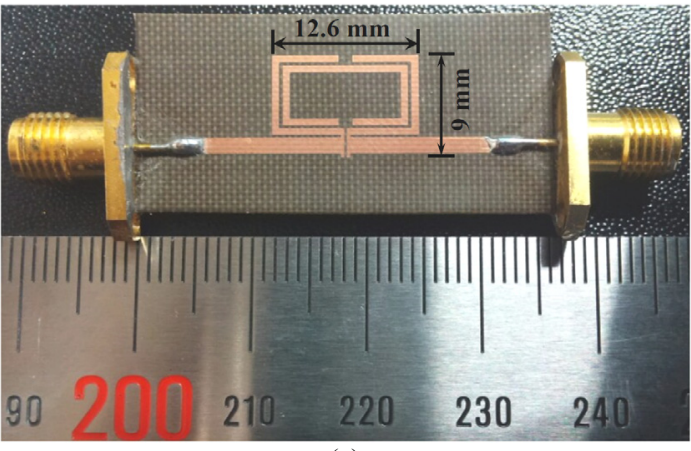

(a)

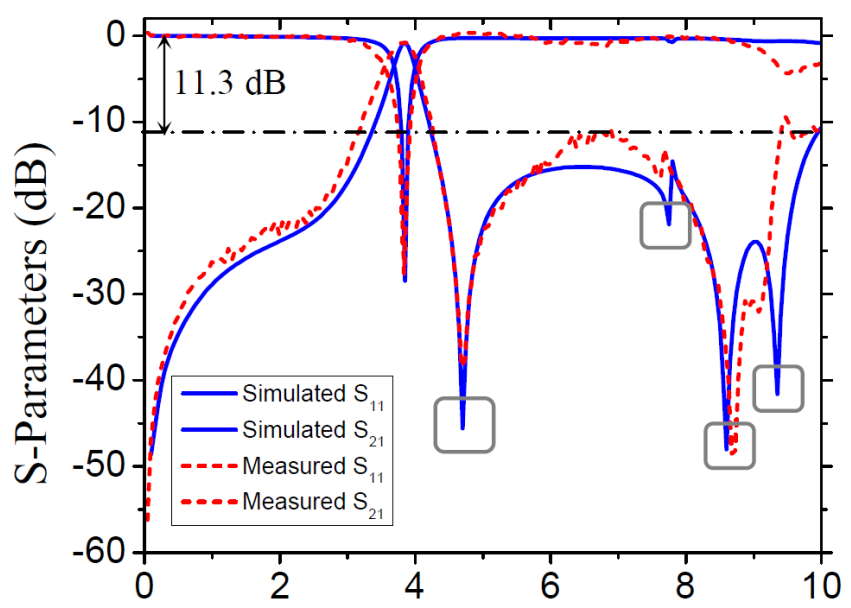

(b)

Fig. 5. Measured results of the fabricated prototype BPF: (a) Schematic of the fabricated prototype BPF, and (b) comparison of the simulated and measured S-parameters.

\begin{tabular}{|c|c|c|c|c|c|c|}
\hline Ref & $\begin{array}{c}\mathrm{CF} \\
{[\mathrm{GHz}]}\end{array}$ & $\begin{array}{c}\mathrm{IL} / \mathrm{RL} \\
{[\mathrm{dB}]}\end{array}$ & $\begin{array}{c}\varepsilon_{\mathrm{r}} / \mathrm{h} \\
{[-] /[\mathrm{mm}]}\end{array}$ & $\begin{array}{c}\text { FBW } \\
{[\%]}\end{array}$ & $\mathrm{TZs}$ & $\begin{array}{c}\text { Size } \\
{\left[\mathrm{mm}^{2}\right]}\end{array}$ \\
\hline 17 & 1.7 & $1.2 / 20$ & $3.55 / 0.508$ & 9.4 & 2 & $16 \times 7.8$ \\
\hline 18 & 2.4 & $0.9 / 10$ & $2.20 / 0.508$ & 8.2 & 2 & $28.4 \times 2.3$ \\
\hline 19 & 2.4 & $1.45 / 21$ & $3.55 / 0.508$ & 10.5 & 2 & $10.4 \times 5.2$ \\
\hline 20 & 5.2 & $1.2 / 22$ & $3.38 / 0.762$ & 19.2 & 2 & $9 \times 6$ \\
\hline 21 & 5.5 & $1.5 / 18$ & $3.55 / 0.508$ & 9.7 & 2 & $8.5 \times 5$ \\
\hline 22 & 5.8 & $0.9 / 22$ & $2.20 / 0.254$ & 8.5 & 3 & $8.6 \times 18.1$ \\
\hline $\begin{array}{c}\text { This } \\
\text { work }\end{array}$ & 3.83 & $0.83 / 27$ & $2.52 / 0.504$ & 12.98 & 4 & $12.6 \times 9$ \\
\hline
\end{tabular}

CF: Center frequency, IL: Insertion loss, RL: Return loss, FBW Fractional bandwidth, TZ: Transmission zeros

Tab. 1. Performance characteristics comparison of the proposed BPF with several reported BPFs.

\section{Multipath Coupled BPF Analysis}

A Teflon substrate with dielectric constant $\varepsilon_{\mathrm{r}}=2.52$, loss tangent $\delta=0.02$, and thickness $h=0.504 \mathrm{~mm}$ was used for the implementation of the proposed BPF with a simulated central frequency of $3.85 \mathrm{GHz}$ and a $3-\mathrm{dB}$ bandwidth of $12.8 \%$. The full-wave electromagnetic simulation was carried out using Sonnet software, and the optimized physical parameters for the BPF with the simulated central frequency of $3.85 \mathrm{GHz}$ and $3-\mathrm{dB}$ bandwidth of $8.31 \%$ are: $l_{\mathrm{x}}=10.8 \mathrm{~mm}, l_{\mathrm{y}}=4.7 \mathrm{~mm}, w=0.6 \mathrm{~mm}, d=$
$1.2 \mathrm{~mm}, W_{\mathrm{C}}=0.6 \mathrm{~mm}, W_{\mathrm{T}}=1.4 \mathrm{~mm}, G=0.2 \mathrm{~mm}, G_{\mathrm{C} 1}=$ $1.2 \mathrm{~mm}, G_{\mathrm{C} 2}=0.2 \mathrm{~mm}, G_{\mathrm{M}}=0.3 \mathrm{~mm}$, and $L=0.4 \mathrm{~mm}$. Figure 5 compares the simulated and measured results. The central frequency of the fabricated filter, tested and characterized using an Agilent $8510 \mathrm{C}$ vector network analyzer (VNA), was $3.83 \mathrm{GHz}$, which was up- and down-shifted by $20 \mathrm{MHz}$ with respect to the simulation. The frequency shifting may be attributed to the dielectric loss of the substrate, dispersion loss at the bends of the resonator, and the accuracy of the physical dimensions [16]. The return and insertion losses of the pass band were measured to be 27.58 and $0.82 \mathrm{~dB}$, respectively. The measured transmission zeros, which were observed at $4.7,7.75,8.6$, and $9.35 \mathrm{GHz}$ with return losses of $45.7,21.9,48.1$, and $41.5 \mathrm{~dB}$, respectively, generated a wide stop-band extending from $100 \mathrm{MHz}$ to $3.17 \mathrm{GHz}$ and $4.21 \mathrm{GHz}$ to $10 \mathrm{GHz}$.

Table 1 indicated that our developed BPF exhibits a noticeable advantage of higher number of transmission zeros, and therefore, better stop-band selectivity than several recently reported BPFs [17-22]. Additionally, the present BPF exhibits a more compact effective size Moreover, the superior pass-band selectivity of the proposed BPF is marked by the lower insertion loss and higher return loss.

\section{Conclusion}

In this letter, a high-selectivity microstrip BPF based on an STSRR was presented. Multipath source-load coupling effects were introduced to improve the in-band and out-of-band selectivity of the proposed BPF by embedding the STSRR inside the capacitively coupled folded signal feeding lines shunt-connected with capacitively coupled transmission lines. The employed multipath coupling effects generated the multiple transmission zeros in the upper stop band and allowed the flexible control of the BFP bandwidth, rendering the proposed method of designing a BPF suitable for various wireless communication applications. A prototype BPF with a measured central frequency of $3.83 \mathrm{GHz}$ and bandwidth of $12.98 \%$ exhibited a compact size of $0.029 \lambda^{2}$.

\section{Acknowledgments}

This research was supported by the Basic Science Research Program through the National Research Foundation of Korea (NRF) funded by the Ministry of Science, ICT and Future Planning (No. 2011-0030079), and by a grant supported by the Korean Government (MEST) (No. 2015R1D1A1A09057081). This work was also supported by a Research Grant from Kwangwoon University in 2018. In addition, this research was also supported by the Korean Government (MEST) (No. 2016K000117). 


\section{References}

[1] PENDRY, J. B., HOLDEN, A. J., ROBBINS, D. J., STEWART, W. J. Magnetism from conductors and enhanced nonlinear phenomenon. IEEE Transactions on Microwave Theory and Techniques, 1999, vol. 47, no. 11, p. 2075-2084. DOI: $10.1109 / 22.798002$

[2] DURAN-SINDREU, M., VELEZ, P., BONACHE, J., et al. Broadband microwave filters based on open split ring resonators (OSSRs) and open complementary split ring resonators (OCSRRs): Improved models and design optimization. Radioengineering, 2011, vol. 20, no. 4, p. 775-783. ISSN 1210-2512

[3] LIU, H., FAN, Y., ZHANG, Z., ZHAO, Y., et al. Dual-band superconducting bandpass filter using embedded split ring resonator. IEEE Transactions on Applied Superconductivity, 2013, vol. 23, no. 03, p. 1-4. DOI: 10.1109/TASC.2012.2230674

[4] HORESTANI, A. K., DURAN-SINDREU, M., NAQUI, J., et al. S-shaped complementary split ring resonators and their application to compact differential bandpass filters with common-mode suppression. IEEE Microwave and Wireless Components Letters, 2014, vol. 24, no. 3, p. 149-151. DOI: 10.1109/LMWC.2013.2291853

[5] VELEZ, P., NAQUI, J., FERNANDEZ-PRIETO, A., et al. Differential bandpass filter with common-mode suppression based on open split ring resonators and open complementary split ring resonators. IEEE Microwave and Wireless Components Letters, 2013, vol. 23, no. 1, p. 22-24. DOI: 10.1109/LMWC.2012.2236083

[6] BONACHE, J., GIL, I., GARCIA-GARCIA, J., MARTIN, F. Novel microstrip bandpass filters based on complementary splitring resonators. IEEE Transactions on Microwave Theory and Techniques, 2006, vol. 54, no. 1, p. 265-271. DOI: 10.1109/TMTT.2005.861664

[7] KIM, E. S., ADHIKARI, K. K., KIM, N. Y. Miniaturized highselectivity microstrip bandpass filter using capacitively coupled stub-loaded stepped-impedance resonators. Microwave and Optical Technology Letters, 2016, vol. 58, no. 8, p. 2004-2010. DOI: $10.1002 /$ mop. 29958

[8] GAO, L., ZHANG, X. Y. High-selectivity dual-band bandpass filter using a quad-mode resonator with source-load coupling. IEEE Microwave and Wireless Components Letters, 2013, vol. 23, no. 9, p. 74-76. DOI: 10.1109/LMWC.2013.2274995

[9] LIANG, J. G., WANG, C., KIM, N. Y. Compact and highly selective dual/tri-band BPFs using folded T-shaped stub-loaded resonators for WLAN and WiMAX applications. Microwave and Optical Technology Letters, 2015, vol. 58, no. 2, p. 312-319. DOI: 10.1102/mop. 29557

[10] LINDEN, S., ENKRICH, C., DOLLING, G., KLEIN, M. W., et al. Photonic metamaterials: magnetism at optical frequencies. IEEE Journal of Selected Topics in Quantum Electronics, 2006, vol. 12, no. 6, p. 1097-1105. DOI: 10.1109/JSTQE.2006.880600

[11] LEE, H. J., LEE, J. H., JUNG, H. I. A symmetric metamaterial element-based RF biosensor for rapid and label-free detection. Applied Physics Letters, 2011, vol. 99, p. 1-3. DOI: 10.1063/1.3653959

[12] ADHIKARI, K. K., KIM. N. Y. Ultrahigh-sensitivity mediator-free biosensor based on a microfabricated microwave resonator for the detection of micromolar glucose concentrations. IEEE Transactions on Microwave Theory and Techniques, 2016, vol. 64, p. 319-327. DOI: 10.1109/TMTT.2015.2503275

[13] LIU, M. Q., WANG, C., KIM, N. Y. A compact dual-bandpass filter using triple-mode stub-loaded resonators and outer-folding open-loop resonators. Indian Journal of Engineering \& Materials Sciences, 2017, vol. 24, p. 13-17. DOI:10.1587/elex.12.20150676
[14] MAKIMOTO, M., YAMASHITA, S. Microwave Resonator and Filter for Wireless Communication: Theory, Design and Application. Berlin (DE): Springer, 2001. ISBN: 978-3-66204325-7

[15] LI, Y., WANG, C., KIM, N. Y. A compact dual-band bandpass filter with high design flexibility using fully isolated coupling paths. Microwave and Optical Technology Letters, 2014, vol. 56, no. 3 , p. $642-646$. DOI: $10.1002 /$ mop. 28170

[16] ADHIKARI, K. K., KIM, N. Y. A miniaturized quad-band bandstop filter with high selectivity based on shunt-connected, Tshaped stub-loaded, stepped-impedance resonators. Microwave and Optical Technology Letters, 2015, vol. 57, no. 5, p. 1129-1132. DOI: $10.1002 /$ mop.29046

[17] DANAEIAN, M., AFROOZ, K., HAKIMI, A. Miniaturization of substrate integrated waveguide filters using novel compact metamaterial unit-cells based on SIR technique. International Journal of Electronics and Communications, 2018, vol. 84, p. 62-73. DOI: 10.1016/j.aeue.2017.11.008

[18] AZAD, A. R., MOHAN, A. Sixteenth-mode substrate integrated waveguide bandpass filter loaded with complementary split-ring resonator. Electronics Letters, 2017, vol. 53, no. 8, p. 546-547. DOI: $10.1049 / \mathrm{el} .2016 .3620$

[19] DANAEIAN, M., GHAYOUMI-ZADEH, H. Miniaturized substrate integrated waveguide filter using fractal open complementary split-ring resonators. International Journal of $R F$ Microwave Computer Aided Engineering. 2018, vol. 28, no. 5, p. 1-10. DOI: $10.1002 /$ mmce. 21249

[20] CHENG, C. C., CHENG, K. X., KUNG, H. K., et al. A compact low insertion loss bandpass filter based on meandered self-coupled ring resonator. In MATEC Web Conference. 2017, vol. 123, DOI: 10.1051/matecconf/201712300016

[21] DANAEIAN, M., AFROOZ, K., HAKIMI, A., MOZNEBI, A. R. Compact bandpass filter based on SIW loaded by open complementary split-ring resonators. International Journal of $R F$ Microwave Computer Aided Engineering, 2016, vol. 26, no. 8, p. 674-682. DOI: $10.1002 / \mathrm{mmce} .21017$

[22] YAN, T., TANG, X. H., XU, Z. X., LU, D. A novel type of bandpass filter using complementary open-ring resonator loaded HMSIW with an electric cross-coupling. Microwave and Optical Technology Letters, 2016, vol. 58, no. 4, p. 998-1001. DOI: 10.1002/mop.29719

\section{About the Authors ...}

Eun-Seong KIM was born in Seoul, Korea in 1994. He received the B.S degree in Computer Science at Kwangwoon University, Seoul, Korea, in 2015 and he is currently preparing toward the Ph.D. degree at Kwangwoon University in RFIC Lab, Seoul, Korea. His current research interests include integrated passive devices (IPDs), LED packaging, bio sensor and humidity sensor.

Kishor Kumar ADHIKARI is currently working as a research associate in the Dept. of Microwave Engineering, School of Astronautics, Harbin Institute of Technology, Heilongjiang, China. He received his Ph.D. in Electronic Engineering from Kwangwoon University, Seoul, South Korea, in 2016. He has published 12 peer-reviewed journal papers, 16 international conference papers, and got registered two research patents. He is the recipient of best student paper (runner up) of IEEE IMWS-Bio 2014 confer- 
ence held in London, United Kingdom. His research interests include microwave resonant biosensors, microfabrication via photolithography, nanomaterial synthesis and their integration with microfabricated biosensors, and conformal biosensors.

Nam Young KIM received two Master's and Ph.D. degrees in Electronic Engineering from the State University of New York (SUNY) at Buffalo, Buffalo, NY, USA, in 1991 and 1994, respectively, the Masters and Ph.D. degree in theology from the Midwest University, St. Louis, MO, USA, in 2004 and 2006, respectively. He was then a Research Scientist with the Center for Electronic and Electro- optic Materials (CEEM), SUNY at Buffalo. In 1994, he joined the Dept. of Electronic Engineering, Kwangwoon University, Seoul, Korea, as a Professor. His main research focus is RF integrated circuits (RFICs), RF nano-devices, and RF nano-bio devices. He is the founder of the RFIC Research Center and also serves as a Director of the Fusion Technology Center, Kwangwoon University. He has leaded the RFIC and compound semiconductor related research group at Kwangwoon University. He has authored or coauthored 275 refereed journal papers, 28 books, and 343 refereed conference papers. He holds over 116 patents and semiconductor design patents. 